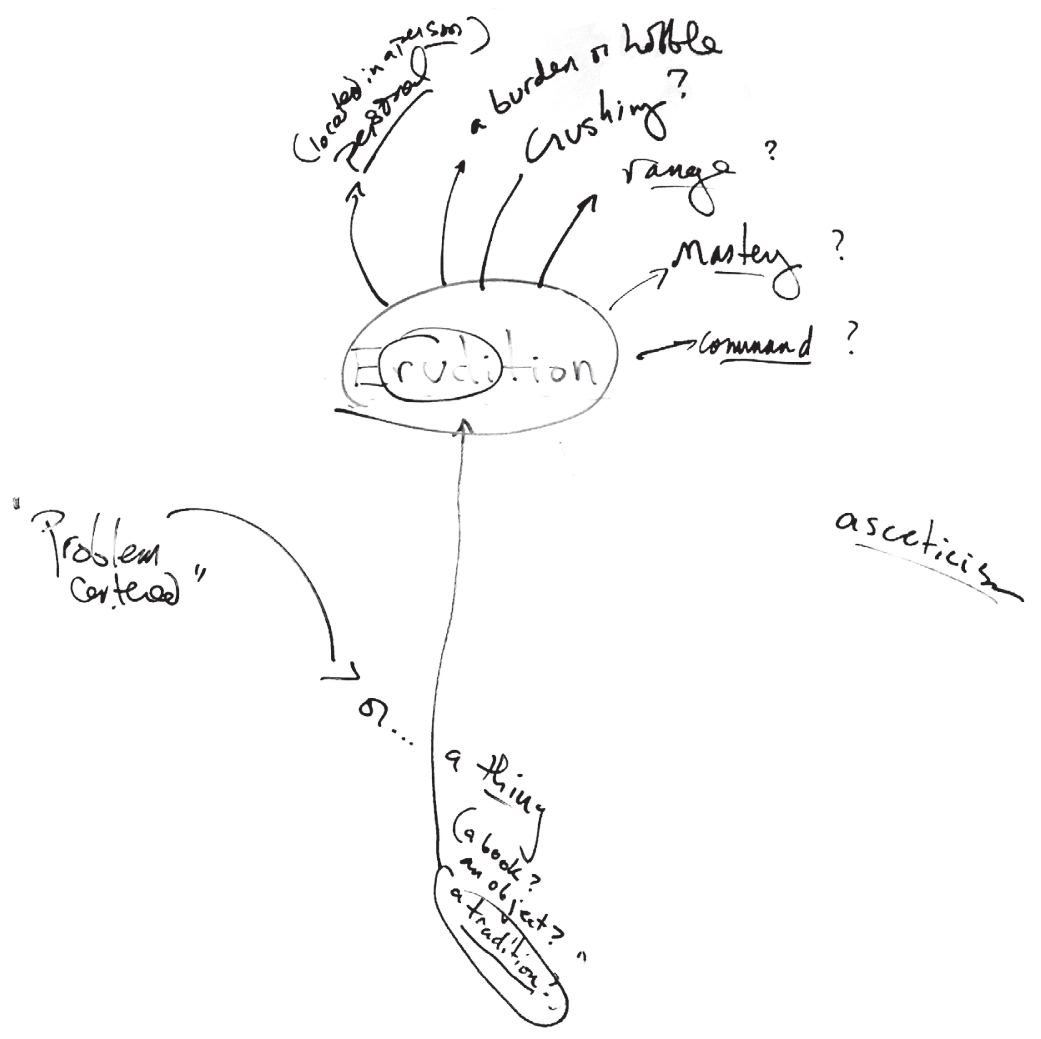



Object

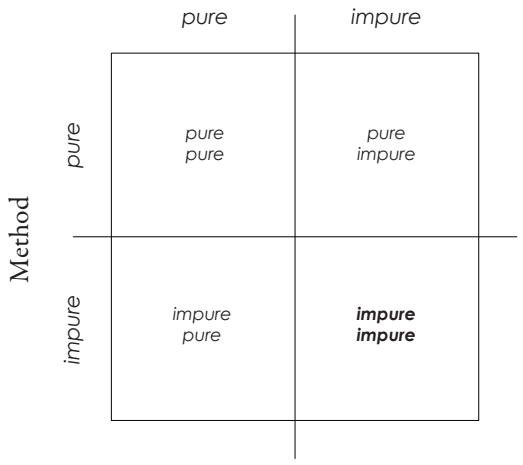





\section{REY WORD足:}

\section{FOR FURTHER CONSIDERATION}

and

PARTICULARLY RELEVANT

†

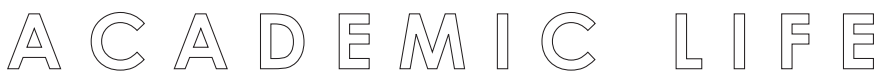

Authored by

A COMMUNITY OF INQUIRY *

IHUM BOOKS

in association with

PRINCETON UNIVERSITY PRESS

$M M X V I I I$ 
Copyright (C) 2018 by IHUM BOOKS

All Rights Reserved

Published by

IHUM BOOKS

Interdisciplinary Doctoral Program in the Humanities at Princeton

Princeton University

Princeton, NJ 08544

princeton.edu/ihum

Distributed by

Princeton University Press

41 William Street

Princeton, NJ 08540

press.princeton.edu

Library of Congress Control Number: 2017958697

ISBN: 978-0-691-18183-7

British Library Cataloguing-in-Publication data is available

* The "Community of Inquiry" consisted of: Paul Baumgardner, D. Graham Burnett Kate Yeh Chiu, Jeff Dolven, Michael Faciejew, Thomas Matusiak, Candela Potente, Matthew Rickard, Jessica Terekhov, and Enzo E. Vasquez Toral

Editors: D. Graham Burnett, Matthew Rickard, and Jessica Terekhov Design: Kate Yeh Chiu

With special thanks to: Christie Henry, Brooke Holmes, Anne Savarese, the IHUM Executive Committee, the Center for Collaborative History, and the Council of the Humanities at Princeton University

This book has been composed in Garamond Premier Pro and Century Gothic

Printed in the United States of America

10987654321 